\title{
Effect of replacing dietary fish meal by cottonseed meal on growth performance and feed utilization of the Nile tilapia, (Oreochromis niloticus)
}

\author{
Magdy A. Soltan ${ }^{1}$, Ahmed F. Fath El-Bab ${ }^{2}$ and Abdel-Nasser M. Saudy ${ }^{3}$
}

1. Faculty of Agriculture, Moshtohor, Banha University, Egypt.

2. Central Laboratory for Aquaculture Research - Abbassa, Sharkyia governorat

3. National Organization for Drug Control and Research, Egypt.

\begin{abstract}
The present study aimed to investigate the effect of partial or complete replacement of the fish meal (FM) by cotton seed meal (CSM) in diets of Nile tilapia, Orcochromis niloticus, to reduce feed costs. Therefore, five experimental diets contained 0, 25, 50, 75 and $100 \%$ CSM as replacements of FM. The final body weight decreased with increasing the level of replacing FM by CSM. However, the replacement of $25 \%$ of FM by CSM had no significant effect on the final BW, while the higher replacing levels $(50,75$ or $100 \%)$ significantly $(\mathrm{P}<0.05)$ reduced the final $\mathrm{BW}$ of the Nile tilapia and the same trend was also observed for body length, weight gain, specific growth rate, feed intake, feed conversion ratio and protein efficiency ratio.

At the experimental termination (90 days), the highest condition factor $(\mathrm{K})$ value was recorded for fish fed on diet 2 (CSM 25\%), followed in a descending order by those fed on the control diet, D1 (CSM 0\%); D5 (CSM 100\%); D3 (CSM 50\%) and D4 (CSM 75\%) respectively. Moreover among the other levels, the final $\mathrm{K}$ values of the Nile tilapia were not significantly affected by replacing levels of dietary FM by CSM.

Hematocrit and haemoglobin values (hematological parameters) were almost decreased proportionally with increasing the dietary CSM protein level. Compared with fish fed the control diet (CSM0), all replacing levels of FM by CSM significantly $(\mathrm{P}<0.05)$ decreased Hematocrit and haemoglobin values and the largest declines occurred for fish fed diets containing 50-100\% CSM protein replacements.

Values of serum transaminases (aspartate aminotransferase, AST and alanine aminotransferase, ALT) almost increased with each increase in CSM level as a substitute for FM in Nile tilapia diets.

Results of proximate analysis of the whole fish body showed that as the dietary CSM level increased, protein content significantly $(\mathrm{P}<0.05)$ decreased while the opposite trend was observed for fat content where the increasing levels of CSM in the experimental diets significantly $(\mathrm{P}<0.05)$ increased fat content of the whole fish body. The inclusion of $25 \% \mathrm{CSM}$ in the experimental diets had no significant effect on ash content while the other replacing levels $(50,75$ and $100 \%$ ) significantly reduced ash content of whole fish body.
\end{abstract}

Keywords: Nile tilapia, (Oreochromis niloticus), growth performance, cotton seed meal, condition factos. 


\section{INTRODUCTION}

The high cost of fish meal in tilapia diets warrants the potential use of cottonseed meal (CSM) as an alternative source of high quality protein. Cottonseed, Gossypium spp, is the third leading legume seed by weight (after soybean and rapeseed) used worldwide. Owing to its high protein value for animals (Alford et al., 1996) as well as low market price in comparison with legumes and fish meal, cottonseed meal (CSM) consequently has an immense potential for incorporation in high-protein aqua-feeds. Cottonseed meal is an important source of dietary protein for domestic animals, its use in commercial aquaculture feeds is limited because of the presence of gossypol (a polyphenolic substrate ) which known with its toxic effect in fish that include growth depression (Garcia-Abiado et al., 2004) and the low available lysine content.

The results of numerous studies evaluating CSM in catfish, salmonid and tilapia diets indicated that between $10 \%$ and $30 \%$ of solvent extracted, $40 \%$ protein CSM can be used in aquaculture diets without growth depression. Lee et al. (2006) summarized a series of studies in rainbow trout where CSM replaced fish meal entirely over a 3-year period without significantly impacting growth rate of rainbow trout, although diets with CSM had significantly lower protein and phosphorus assimilation. In the study of Robinson and Li (1994), channel catfish, Ictalurus punctatus, were raised at high densities in earthen ponds and fed to satiation a diet containing 51\% CSM with supplemented lysine $(0.65 \%)$. Results of there authors indicated that growth rate, dress-out percentage and chemical composition of the fillets did not differ significantly from fish fed diets containing SBM (42\%). Cottonseed meal typically contains about $400-800 \mathrm{mg}$ of free gossypol $\mathrm{kg}^{-}{ }^{-}$, a compound recognized for its toxicity to animals, especially in regard to reproduction.

Robinson and Tiersch (1995) found that mature catfish fed diets containing CSM at either $37.5 \%$ or $52 \%$ (300 or $400 \mathrm{mg}$ of free gossypol kg- ${ }^{-1}$ diet) gained less weight than fish fed either a control diet (no CSM) or a diet with 25\% CSM. Gossypol concentrations in liver were proportional to dietary CSM levels. Free gossypol is known to bind lysine rendering it less bioavailable (Wilson et al., 1981).

Growth depression occurred in channel catfish fed diets containing more than $900 \mathrm{mg}$ free gossypol/kg diet (Dorsa et al., 1982), whereas a diet containing as low as $290 \mathrm{mg}$ free gossypol $/ \mathrm{kg}$ diet reduced the growth of rainbow trout (Herman, 1970). Iron as ferrous sulfate, has been successfully used to counteract the toxicity of free gossypol in diets of monogastric, terrestrial animals (Jones, 1987). High levels of supplemental iron used to counteract the toxicity of gossypol may be harmful to fish because it has been suggested that a delicate balance exists between the need of iron for host defense mechanisms and the need of iron to sustain microbial growth.

Garcia Abiado et al. (2004) reported that, fish fed on 25-50\% CSM protein replacement showed similar body weight and total lengths as the controls at the completion of the 16-week trial. Fish fed 75 and 100\% CSM protein replacement 
showed a significant decline in body weight and total length. They added that Fish fed $25-100 \%$ CSM protein replacement had significantly lower haematocrit and hemoglobin values compared with levels in controls.

Early studies have indicated that the amount of CSM that can be used in Nile tilapia feed depends mainly on the level of free gossypol and available lysine content of the diets. Due to unfavorable physiological effects of gossypol and to a reduction in the biological availability of lysine because of the binding properties of gossypol (Dorsa et al., 1982), application of higher levels of CSM in fish diets is limited. Ofojekwu and Ejike (1984) and Rosbinson et al. (1984 a) found that $O$. arueus fed CSM-based diets yield poor performance. The authors attributed the poor performance to the gossypol contents in glanded and glandless CSM, respectively. On the contrary repressed solvent-extracted CSM was successfully used as a single dietary protein source for O. mossambicus (Jackson et al. 1982) and Nile tilapia (El-Sayed 1990). El-Saidy (1999) reported that, rapressed solvent-extracted CSM could replace up to $50 \%$ of FM in juvenile Nile tilapia diets without requiring lysine supplementation. Free gossypol when present in large quantity in the diet has been shown to be toxic to monogastric animals including fish. The present study aimed to evaluate the effect of partial or complete replacement of fish meal (FM) by cotton seed meal (CSM) in diets on growth performance and feed utilization of Nile tilapia Oreochromis niloticus.

\section{MATERIALS AND METHODS}

The present study was carried out at the Laboratory of Fish Nutrition, Faculty of Agriculture, Benha University. The experiment was conducted during the period from 15 April until 15 July 2006 (three months), designed to study the effect of replacing FM partially or completely by CSM in Nile tilapia diets on growth performance, nutrients utilization, chemical composition and feeding costs. .

\section{Experimental Fish and Management}

The experimental fish were obtained from the hatchery unit at the Experimental Station of the World Fish Center, Abbassa, Abou Hammad, Sharkia, Egypt. The experimental fish were carefully transported in 50 -liter plastic bags filled with water and oxygen to the laboratory. After arrival fish were adapted for 2 weeks to the new conditions, and fed a basal diet containing $40 \% \mathrm{CP}$ and $3000 \mathrm{Kcal} \mathrm{ME} / \mathrm{Kg}$ diet. Fish were randomly grouped into 5 groups and each group was arranged in three glass aquaria (three replicates for each treatment) therefore, 15 rectangular aquaria $100 \mathrm{~L} \times 40 \mathrm{~W} \times 50 \mathrm{H}, \mathrm{cm}(180$ liter of water for each) were used for this experiment. Each aquarium was stocked with 20 fish with an initial weight raring from 1.43 to $1.53 \mathrm{~g}$, therefore, a total of 300 fish of Nile tilapia (Oreochromis niloticus) was used in the present investigation.

About $25 \%$ of water volume in each aquarium was daily replaced by aerated fresh water after cleaning and removing the accumulated excreta. Water, 
temperature, $\mathrm{pH}$ and dissolved oxygen were measured daily at $2.00 \mathrm{pm}$, while total ammonia was weekly measured. Water quality parameters measured were found to be within acceptable limits for fish growth and health (Boyd, 1979).

Fish were fed experimental diets at a daily rate of $3 \%$ of total biomass till the end of experimental period. Fish were fed on the experimental diets at the rate mentioned above six day/week (twice daily). Every two weeks, fish were taken from each aquarium then weighed and the amount of feed was adjusted according to the changes in body weight through the experimental period.

\section{Experimental Diets}

Five experimental diets contained $0 \%, 25 \%, 50 \%, 75 \%$ and $100 \%$ CSM as replacements of FM on protein basis were used in the experiment (D1, CSM $0 \%$; D2, CSM 25\%; D3, CSM 50\%; D4, CSM 75\% and D5, CSM 100\%). All experimental diets were formulated to contain approximately $30 \% \mathrm{CP}$ and 2700 $\mathrm{Kcal} \mathrm{ME} / \mathrm{Kg}$ diet, i.e., isonitrogenous and isocaloric. Feed ingredients and chemical composition of the experimental diets are shown in Table (1). The dry ingredients of the experimental diets were first ground to a small particle size, thoroughly mixed, then water was added to obtain a $30 \%$ moisture level. Diets were passed through a mincer machine with $2 \mathrm{~mm}$ diameter after which the diets were sun-dried for 3 days.

\section{Growth performance and feed utilization parameters}

Records of live body weight $(\mathrm{BW}, \mathrm{g})$ and body length $(\mathrm{BL}, \mathrm{cm})$ of individual fish were measured for all fish of each aquarium and registered every 14 days (two weeks) feed utilization and growth parameters were calculated by the following equations:

Weight gain (WG) =Final weight $(\mathrm{g})$ - Initial weight $(\mathrm{g})$.

Condition factor $(\mathbf{K})=\mathrm{BW} /(\mathrm{BL})^{3}$, Where; $\mathrm{BW}=$ Fish weight $(\mathrm{g}) ; \mathrm{BL}=$ Fish length $(\mathrm{cm})$

Specific growth rate $(\mathbf{S G R})=\left[\left(\mathrm{LnW}_{2^{-}} \mathrm{LnW}_{1}\right) / \mathrm{T}\right] \times 100$, Where; $\mathrm{Ln}=$ The natural $\log ; \mathrm{W}_{2}=$ Final fish weight at certain period $(\mathrm{g}) ; \mathrm{W}_{1}=$ Initial fish weight at the same period (g) T=Period (day)

Feed conversion ratio $($ FCR $)=$ Feed intake $(\mathrm{g}) /$ Weight gain $(\mathrm{g})$

Protein efficiency ratio $($ PER) $=$ Weight gain $(\mathrm{g}) /$ protein intake $(\mathrm{g})$

Blood Sampling.

At the end of the experiment (90 days after start), eight fish were chosen at random from each aquarium and sacrified with a sharp knife. Blood samples of four fish were collected from the caudal vein in clean heparinized tube, to determine hematocrit and hemoglobin. Blood samples of the other four fish were collected also from the caudal vein in clean dry centrifuge tubes, kept for 15 minutes, centrifuged at $3000 \mathrm{rpm}$. for 10 minutes to separate blood serum, then kept frozen at $-20^{\circ} \mathrm{C}$ for latter determination of blood serum transaminases.

Hematocrit was determined by the microhematocrit method as described by Reitman and Frankel (1957). Whereas, hemoglobin was determined by the total hemoglobin kits, which is a standardized procedure of the 
cyanomethemoglobin method. All biochemical analysis of fish serum were measured colorimetrically using spectrophotometer, and commercial kits Asparatate aminotransferase (AST) and alanine aminotransferase (ALT) activities were determined according to the method described by Reitman and Frankel (1957).

All the experimental diets were chemically analyzed to determine dry matter $(\mathrm{DM})$, crude protein $(\mathrm{CP}, \mathrm{N} \times 6.25)$, ether extract $(\mathrm{EE})$, crude fiber $(\mathrm{CF})$, and ash contents according to the methods of the AOAC (1990). Nitrogen free extract (NFE) was calculated by differences, i.e.; by deducting the sum of percentages of moisture, CP, EE, CF and ash from 100.

After blood sampling, the eight fish chosen from each aquarium were exposed to the chemical composition of whole fish body according to the methods of AOAC (1990).

Table 1: Feed ingredients and chemical composition of the experimental diets

\begin{tabular}{|c|c|c|c|c|c|}
\hline \multirow{2}{*}{ Ingredients } & \multicolumn{5}{|c|}{ Experimental diets } \\
\hline & CSM0 & CSM25 & CSM50 & CSM75 & CSM100 \\
\hline Fish meal $(60 \%)$ & 20 & 15 & 10 & 5 & 0 \\
\hline Soy bean meal $44 \%$ & 30 & 30 & 30 & 30 & 30 \\
\hline Yellow corn & 35 & 35 & 35 & 35 & 35 \\
\hline Cottonseed meal & 0 & 6.5 & 13 & 19.5 & 26 \\
\hline Corn oil & 2 & 2 & 2 & 2 & 2 \\
\hline Wheat bran & 10 & 8.5 & 7 & 5.5 & 4 \\
\hline Vit. And min. mix & 3 & 3 & 3 & 3 & 3 \\
\hline Total & 100 & 100 & 100 & 100 & 100 \\
\hline \multicolumn{6}{|c|}{ Chemical composition (on DM basis) } \\
\hline $\mathrm{CP}$ & 30.36 & 30.24 & 30.12 & 30.00 & 29.88 \\
\hline $\mathrm{EE}$ & 4.44 & 5.11 & 4.74 & 4.81 & 5.00 \\
\hline Ash & 8.32 & 8.71 & 8.65 & 8.82 & 9.12 \\
\hline $\mathrm{CF}$ & 5.35 & 5.66 & 5.68 & 6.95 & 6.22 \\
\hline $\mathrm{NFE}^{2}$ & 51.53 & 50.28 & 50.81 & 49.42 & 49.78 \\
\hline $\mathrm{ME}(\mathrm{Kcal} / \mathrm{kg} \operatorname{diet})^{3}$ & 2748 & 2734 & 2720 & 2706 & 2692 \\
\hline $\mathrm{P} / \mathrm{E} \mathrm{ratio}^{4}$ & 110.48 & 110.61 & 110.74 & 110.88 & 111 \\
\hline Price $/ \mathrm{Kg} \operatorname{diet}(\mathrm{LE})^{5}$ & 3.42 & 2.87 & 2.32 & 1.77 & $\underline{1.22}$ \\
\hline
\end{tabular}

${ }^{1}$ Each 1kgof vitamins and minerals mixture contains : Vitamin $\mathrm{D}_{3}, 0.8$ million IU; A, 4.8 million IU; E, 4 g; K, 0.8 g; B1, 0.4 g; Riboflavin, 1.6 g; B6, 0.6 g; B12, 4 mg; Pantothenic acid, 4 g; Nicotinic acid, 8 g; Folic acid, 0.4 g; Biotin, 20 mg; Mn, 22 g; Zn, 22 g; Fe, 12 g; $\mathrm{Cu}, 4 \mathrm{~g}$; I, $0.4 \mathrm{~g}$; Selenium, $0.4 \mathrm{~g}$ and $\mathrm{Co}, 4.8 \mathrm{mg}$.

${ }^{2} \mathrm{NFE}=100-(\mathrm{CP}+\mathrm{EE}+\mathrm{CF}+$ Ash $)$

${ }^{3} \mathrm{ME}$ was calculated from ingredients based on NRC (1993) values for tilapia.

${ }^{4} \mathrm{P} / \mathrm{E}$ ratio $=\mathrm{mg}$ protein $/ \mathrm{Kcal} \mathrm{ME}$

${ }^{5}$ Local market price of feed ingredients used for formulating the experimental diets at the exact time of the experiment was $12000,1200,1000,1000,3000,1000$, and $5000 \mathrm{LE} /$ ton for fish meal, soybean meal, yellow corn, cottonseed meal, corn oil, wheat bran and Vit. and min. mix., respectively. 


\section{Statistical Analysis.}

Statistical analysis of data obtained was analyzed according to the computer program, SAS (1996). Differences between means were tested for significance according to Duncan's multiple rang test as described by Duncan (1955). The following model was used to analyze data obtained of the experiment.

$$
\mathrm{Y}_{\mathrm{ij}}=\mu+\alpha_{\mathrm{i}}+\mathrm{e}_{\mathrm{ij}}
$$

Where; $Y_{i j}=$ the observation of the $j^{\text {th }}$ fish eaten $i^{\text {th }}$ diet; $\mu=$ overall mean; $\alpha_{i}=$ the effect of $j^{\text {th }}$ treatment. $e_{i j}=$ random error assumed to be independently and randomly distributed $\left(0, \delta^{2} \mathrm{e}\right)$.

\section{Growth performance}

\section{RESULTS AND DISCUSSION}

Results of Table (2) indicated that the average initial body weight (BW) of Nile tilapia, O. niloticus ranged between 1.43 and $1.53 \mathrm{~g}$. Analysis of variance showed insignificant differences in initial BW among the experimental fish groups indicating the random distribution of the experimental fish on the different treatments. At experimental termination (after 90 days from the experimental start), the final BW ranged between 6.32 and $11.96 \mathrm{~g}$ and the differences were significant $(\mathrm{P}<0.05)$

Compared with the control fish group, the replacement of $25 \%$ of FM by CSM had no significant effect on the final BW, while the higher replacing levels $(50,75$ and $100 \%)$ reduced significantly $(\mathrm{P}<0.05)$ the final $\mathrm{BW}$ of Nile tilapia and the same trend was also observed for body length.

Nearly similar results were reported by Garcia-Abiado et al. (2004). who found that tilapia fish fed $25-50 \%$ CSM protein as a replacer of FM showed similar body weight and length (BL) as the controls at the completion of a 16week trial, while fish fed 75 and $100 \%$ CSM protein replacement showed a significant decline in BW. On the other hand, Rinchard et al. (2003) concluded that final BW and BL of rainbow trout fish was not affected when dietary FM proteins were gradually replaced with CSM proteins $(0,25,50,75$ and $100 \%)$ during a 9-month period.

The initial value of condition factor ( $\mathrm{K}$ values) for fish received the experimental diets ranged between 2.69 and 3.02 with insignificant differences, indicating that tilapia fry at the experimental start had relatively similar BW and BL (Table 2). At the experimental termination, the highest $\mathrm{K}$ value (2.24) was recorded for fish group fed diet 2 (CSM 25) where $25 \%$ of FM was replaced by CSM followed in a descending order by those fed the control diet 1 (CSM0) 2.07, diet 5 (CSM100) 2.06, diet3 (CSM50) 2.04, and diet 4 (CSM 75) 1.95 respectively. Analysis of variance indicate that final $\mathrm{K}$ values of Nile tilapia were not significantly $(\mathrm{P}>0.05)$ affected by the replacing levels of dietary FM by CSM.

Growth in the fish can be readily monitored by measuring the increase in weight and length. Another parameter which may be used as index for growth is 
the $\mathrm{K}$, which provides a measure of fattiness of fish and feed conversion efficiency (Power, 1990). Condition factor also measures the plumpness or robustness of fish, and easily calculated from routinely collected length and weight data. Condition factor of fish is essentially a measure of relative muscle to bone growth and the differing growth responses of these tissues to diet treatment may be reflected by changes in $\mathrm{K}$ value (Ostrowski and Garling, 1988). Condition factor was considered to be a sufficient measure of shape, although shape is usually not considered as a character of interest to breeding programmes, since it has no obvious economic value (Nilsson, 1992).

Table 2: Least square means and standard error for the effect of replacing fish meal by cottonseed meal in Nile tilapia diets on body weight, body length and condition factor.

\begin{tabular}{|l|c|c|c|c|c|c|c|}
\hline \multirow{2}{*}{ Diets } & \multirow{2}{*}{ No. } & \multicolumn{2}{|c|}{ Body weight ,g. } & \multicolumn{2}{c|}{ Body length ,cm. } & \multicolumn{2}{c|}{ Condition factor } \\
\cline { 3 - 8 } & & Initial & Final & Initial & Final & Initial & Final \\
\hline Diet1 (Control) & 60 & 1.43 & $11.96 \mathrm{a}$ & 3.77 & $8.32 \mathrm{a}$ & 2.69 & 2.07 \\
\hline Diet2 (CSM25) & 60 & 1.53 & $10.54 \mathrm{ab}$ & 3.83 & $7.80 \mathrm{ab}$ & 2.73 & 2.24 \\
\hline Diet3 (CSM50) & 60 & 1.53 & $8.93 \mathrm{~b}$ & 3.75 & $7.58 \mathrm{bc}$ & 2.92 & 2.04 \\
\hline Diet4 (CSM75) & 60 & 1.47 & $6.99 \mathrm{c}$ & 3.65 & $7.11 \mathrm{~cd}$ & 3.02 & 1.95 \\
\hline Diet5 (CSM100) & 60 & 1.48 & $6.32 \mathrm{c}$ & 3.74 & $6.75 \mathrm{~d}$ & 2.84 & 2.06 \\
\hline Standard error & & \pm 0.06 & \pm 0.43 & \pm 0.08 & \pm 0.20 & \pm 0.21 & \pm 0.11 \\
\hline
\end{tabular}

Averages followed by different letters in the same column are significantly $(\mathrm{P}<0.05)$ different.

In an earlier study, Robinson and Daniels (1987) investigated CSM as a partial or complete substitute for soybean meal in catfish diets. They reported that fish fed a diet containing CSM to replace all soybean meal had similar K values compared to fish fed a soybean meal diet.

Results in Table (3) showed that the highest weight gain (WG) value (10.54g) was recorded by fish group fed on the control diet (CSM 0), while the lowest one (4.84g) was shown by fish group fed on diet 5, CSM100 (complete replacement of FM by CSM). Data obtained indicated that WG values decreased as the level of replacing FM by CSM increased. The effect of the replacing level of dietary FM by CSM on WG was significant $(\mathrm{P}<0.001)$. Differences in WG of fish fed the control diet (CSM 0) and those fed diet 2 (CSM 25) were not significant, whereas, the differences between fish on fed the control diet and those fed on other diets with higher inclusion CSM levels were significant $(\mathrm{P}<0.05)$ and these results are in partial agreement with those reported by Cheng and Hardy (2002). They found that rainbow trout fish fed on the diets containing either $5 \%$ or $10 \%$ CSM (as replacer for dietary FM) had the same WG and were not significantly different from that recorded for fish fed the control FM diet, while the higher replacing levels $(15 \%$ or $20 \%)$ significantly reduced WG compared to fish fed the FM as a control diet. They concluded that CSM could be used up to the $10 \%$ inclusion rate or to replace up to $40 \%$ of FM protein in rainbow trout diets without significant effect on $\mathrm{WG}$. 
Robinson and Tiersh (1995) found that mature catfish fed on diets containing $37.5 \%$ or $52 \%$ of CSM (300 or $400 \mathrm{mg}$ free gossypol $/ \mathrm{kg}$ of feed), gained less weight than fish fed on either control diet (no CSM) or a diet with 25\% CSM.

Yildirim et al. (2003) supplemented juvenile channel catfish diets with 0 , $300,600,900,1200$ and $1500 \mathrm{mg}$ gossypol $/ \mathrm{kg}$ diet and fish were fed the experimental diets to satiation for 12 weeks. They found that WG was inversely related to the concentration of dietary gossypol. Fish fed diets without and with $1500 \mathrm{mg}$ gossypol/kg had significantly the highest and lowest WG values, respectively. In contrast, Rinchard et al. (2003) showed that WG of rainbow trout fish was not affected with increasing levels of replacing dietary FM proteins by CSM proteins (0, 25, 50, 75 and 100\%). Robinson (1991) evaluated the effect of supplementing lysine to CSM when it partially or completely replaced soybean in channel catfish feeds. They found that CSM could replace $50 \%$ of soybean meal without lysine supplementation, and could replace $100 \%$ of soybean meal when lysine was supplemented, without reducing WG.

Results of Table (3) indicated that, specific growth rate (SGR) values decreased with increasing the level of replacing dietary FM protein by CSM. Fish fed the diet 5 (CSM100) showed the lowest SGR value (1.62), whereas, those fed diet 1 (CSM 0, control diet) recorded the highest one (2.36). in this respect Rinchard et al. (2003) fed rainbow trout during a 9-month period, five experimental diets where FM proteins were gradually replaced with CSM proteins $(0,25,50,75$ and $100 \%$, respectively). SGR of fish was not affected with the increasing levels of CSM in the diets.

Table (3): Least square means and standard error for the effect of replacing fish meal

by cottonseed meal in Nile tilapia diets on weight gain and specific growth rate.

\begin{tabular}{|l|c|c|c|}
\hline Diets & No. + & Weight gain (g/fish) & Specific growth rate \\
\hline Diet1 (Control) & 3 & $10.54 \pm 0.42 \mathrm{a}$ & $2.36 \pm 0.04 \mathrm{a}$ \\
\hline Diet2 (CSM25) & 3 & $9.01 \pm 0.42 \mathrm{ab}$ & $2.21 \pm 0.04 \mathrm{a}$ \\
\hline Diet3 (CSM50) & 3 & $7.40 \pm 0.42 \mathrm{~b}$ & $1.97 \pm 0.04 \mathrm{~b}$ \\
\hline Diet4 (CSM75) & 3 & $5.53 \pm 0.42 \mathrm{c}$ & $1.74 \pm 0.04 \mathrm{c}$ \\
\hline Diet5 (CSM100) & 3 & $4.84 \pm 0.42 \mathrm{c}$ & $1.62 \pm 0.04 \mathrm{c}$ \\
\hline
\end{tabular}

Averages followed by different letters in the same column are significantly $(\mathrm{P}<0.05)$ different. + Average of three replicates (aquaria).

Lee et al. (2002) found that FM could be entirely replaced by a mixture of plant protein $(\mathrm{CSM}+$ soybean meal) without adverse effect on growth rate of rainbow trout, Oncorhynchus mykiss. Lee et al. (2006) replaced FM by CSM at rates of $25,50,75$ and $100 \%$ in experimental diets of rainbow trout (Oncrhynchus mykiss). They found that growth rate was not significantly affected by the dietary CSM except for the diet in which FM was completely replaced by CSM. 
Generally, results of growth performance of Nile tilapia in the present study showed that, replacement of $25 \%$ of FM by CSM (on CP basis) had no significant affect on all growth parameters studied (BW, BL, K, WG and SGR) indicating the possibility of substitution of $25 \%$ of FM protein by CSM protein in Nile tilapia diets without depression of growth, while the higher replacing levels $(50,75$ and 100) significantly depressed all these parameters because the increasing subsuming levels of FM by CSM may increase the amount of gossypol in the diet and followed by depression in fish growth.

\section{Feed utilization}

Results of feed intake (FI) as affected by replacing dietary FM by CSM are presented in Table (4). Feed intake during the entire experimental period (90 days) decreased almost in a linear manner with each increase in dietary CSM level as replacer of FM being 15.91, 14.30, 13.46, 11.59 and $10.65 \mathrm{~g} /$ fish while values of FCR increased from 1.51 to $1.59,1.86,2.10$ and 2.26 for fish fed diets CSM 0, CSM 25, CSM 50, CSM 75 and CSM 100, respectively indicating that FCR values increased (adversed) as dietary CSM level increased.

In this connection the previous results, Cheng and Hardy (2002) showedthat rainbow trout fish fed diets contained either $5 \%$ or $10 \%$ dietary CSM as replacer for FM had the same FCR and were not significantly different from that recorded for fish fed the control $(100 \% \mathrm{FM})$ diet, while the higher replacing levels $(15 \%$ or $20 \%)$ adversed significantly FCR value. They concluded that CSM could be used up to the $10 \%$ inclusion rate or to replace up to $40 \%$ of $\mathrm{FM}$ protien in rainbow trout diets without significant effect on FCR.

Table 4: Least square means and standard error for the effect of replacing fish meal by cottonseed meal in Nile tilapia diets on feed intake, feed conversion ratio and protein efficiency ratio.

\begin{tabular}{|l|c|c|c|c|}
\hline \multicolumn{1}{|c|}{ Diets } & No.+ & $\begin{array}{c}\text { Feed intake } \\
\text { (g/fish) }\end{array}$ & $\begin{array}{c}\text { Feed conversion } \\
\text { ratio }\end{array}$ & $\begin{array}{c}\text { Protein } \\
\text { efficiency ratio }\end{array}$ \\
\hline Diet1 (Control) & 3 & $15.91 \pm 0.47 \mathrm{a}$ & $1.51 \pm 0.03 \mathrm{~d}$ & $2.18 \pm 0.003 \mathrm{a}$ \\
\hline Diet2 (CSM25) & 3 & $14.30 \pm 0.47 \mathrm{ab}$ & $1.59 \pm 0.03 \mathrm{~d}$ & $2.08 \pm 0.003 \mathrm{a}$ \\
\hline Diet3 (CSM50) & 3 & $13.46 \pm 0.47 \mathrm{~b}$ & $1.86 \pm 0.03 \mathrm{c}$ & $1.83 \pm 0.003 \mathrm{~b}$ \\
\hline Diet4 (CSM75) & 3 & $11.59 \pm 0.47 \mathrm{c}$ & $2.10 \pm 0.03 \mathrm{~b}$ & $1.59 \pm 0.003 \mathrm{c}$ \\
\hline Diet5 (CSM100) & 3 & $10.65 \pm 0.47 \mathrm{c}$ & $2.26 \pm 0.03 \mathrm{a}$ & $1.53 \pm 0.003 \mathrm{c}$ \\
\hline
\end{tabular}

Averages followed by different letters in the same column are significantly $(\mathrm{P}<0.05)$ different.

+ Average of three replicates (aquaria).

Ofojekwu and Ejike (1984) reported a much lower (poorer) feed efficiency value for $O$. niloticus fed a CSM diet as compared to tilapia fed a FM control diet. Dietary inclusion levels of $20-30 \%$ CSM have been reported to be both safe and useful for tilapia fish (Robinson et al., 1984). Robinson and Daniels (1987) reported that CSM could be used as complete substitute for soybean meal in catfish diets without significant effect on FCR values. Moreover, Robinson (1991) showed that CSM could replace $50 \%$ of soybean meal without lysine 
supplementation, and could replace $100 \%$ of soybean meal when lysine was supplemented, without reducing FCR values of channel catfish.

Results of Table (4) indicated that, fish fed the control diet (CSMO) showed the highest (best) PER value (2.18), while those fed diet 5 (CSM100) recorded the lowest (poorest) one, being 1.53 . However, replacing $25 \%$ of dietary FM by CSM had no significant effect on PER values, whereas increasing the replacing level to 50,75 or $100 \%$ significantly $(\mathrm{P}<0.05)$ decreased PER values. Lee et al., (2002) found that FM could be entirely replaced by a mixture of plant protein $(\mathrm{CSM}+$ soybean meal) without adverse effect on feed and protein utilization of rainbow trout, Oncorhynchus mykiss..

Based on results of the effect of replacing dietary FM by CSM on FI, FCR and PER of Nile tilapia, it is clear that replacing 25\% of dietary FM by CSM had no significant effect on all of these parameters, whereas, increasing the replacing level to 50,75 or $100 \%$ significantly adverse these parameters.

\section{Hematological parameters}

As described in Table (5), hematocrit and haemoglobin values (hematological parameters) almost decreased proportionally with increasing the dietary CSM protein level. Compared with fish fed the control diet (CSM0), all replacing levels of dietary FM by CSM significantly $(\mathrm{P}<0.05)$ decreased hematocrit and haemoglobin values and the largest declines occurred among fish fed diets containing 50-100\% CSM protein replacement. However, the hematocrit $(27.64 \%)$ and haemoglobin $(9.09 \mathrm{~g} / \mathrm{dl})$ levels of tilapia fish fed the control diet in this study are within the normal levels reported by Sun et al. (1995). Lee et al. (2006) reported that CSM at rates of 25, 50, 75 and 100\% as replacers for dietary FM of rainbow trout had no polynomial effect on hematocrit and hemoglobin concentrations.

In full agreement with the obtained results, Garcia-Abiado et al. (2004) reported that tilapia fish fed diets in which FM was replaced by CSM in an increasing levels $(25,50,75$ or $100 \%$ ) had significantly lower hematocrit and haemoglobin levels compared to levels of the controls. Also, Post (1987) cleared that hematocrit and haemoglobin levels in fish fed diets containing 25-50\% CSM protein were about two to three times lower, whereas the levels in diets containing 75-100\% CSM protein were four to six times lower than controls.

Cytotoxic effects of gossypol are frequently associated with decreased hematocrit and hemoglobin, and increased red blood cell fragility. The reason for the detrimental effects of CSM on hematological parameters (hematocrit and hemoglobin) is thought to be the binding property of gossypol molecules to minerals (iron) and/or the amine group of amino acids causing their low availabilities in the body and increased erythrocyte fragility (Makinde et al., 1997).

Lee et al. (2002) found that hematocrit levels were significantly lower in rainbow trout fish fed CSM-containing diets than in the control and they attributed the lower hematocrit levels observed in fish to the cumulative effect of 
gossypol and/or decreased availability of iron in CSM containing diets causing increased erythrocyte fragility. The gradual increment of gossypol concentrations in blood plasma of fish fed diets containing gradual increases of CSM supports the association of gossypol with decreased hematocrit and hemoglobin levels.

Barraza et al. (1991) reported that the haematological variables, hematocrit and haemoglobin, are important measures as indicators for the rate of haemoglobin synthesis to red cell formation, and erythrocyte sedmentation rate. They added that free gossypol traps Fe, causing anemia and erythrocyte fragility.

Table 5: Least square means and standard error for the effect of replacing fish meal by cottonseed meal in Nile tilapia diets on hematological parameters.

\begin{tabular}{|l|c|c|c|}
\hline Diets & No. + & Hematocrit, \% & Hemoglobin, g/dl \\
\hline Diet1 (Control) & 12 & $27.64 \pm 0.65 \mathrm{a}$ & $9.09 \pm 0.16 \mathrm{a}$ \\
\hline Diet2 (CSM25) & 12 & $23.65 \pm 0.65 \mathrm{~b}$ & $8.07 \pm 0.16 \mathrm{~b}$ \\
\hline Diet3 (CSM50) & 12 & $20.26 \pm 0.65 \mathrm{c}$ & $7.07 \pm 0.16 \mathrm{c}$ \\
\hline Diet4 (CSM75) & 12 & $20.94 \pm 0.65 \mathrm{c}$ & $6.86 \pm 0.16 \mathrm{c}$ \\
\hline Diet5 (CSM100) & 12 & $19.27 \pm 0.65 \mathrm{c}$ & $6.28 \pm 0.16 \mathrm{~d}$ \\
\hline
\end{tabular}

Averages followed by different letters in the same column are significantly $(\mathrm{P}<0.05)$ different. + Average of 12 fish (four fish from each aquarium).

\section{Serum transaminases}

Results of serum transaminases (aspartate aminotransferase, AST and alanine aminotransferase, ALT) of Nile tilapia as affected by replacing dietary FM by CSM are presented in Table (6). These results revealed that AST and ALT values almost increased with each increase in CSM level as a substitute for FM in Nile tilapia diets and the differences in both AST and ALT values attributed to CSM level were significant $(\mathrm{P}<0.05)$. However, AST level (compared to the control group) was not significantly affected when 25 or $100 \%$ of dietary FM was replaced by CSM, while the other replacing levels $(50$ or $75 \%)$ significantly $(\mathrm{P}<0.05)$ increased AST level. With respect to ALT activity, results indicated that increasing CSM level in tilapia diet up to $75 \%$ did not significantly altered ALT level, whereas, the complete replacement of dietary FM by CSM reduced serum ALT level.

Table 6: Least square means and standard error for the effect of replacing fish meal by cottonseed meal in Nile tilapia diets on serum transaminases (AST and ALT).

\begin{tabular}{|l|c|c|c|}
\hline Diets & No. $^{+}$ & AST $(\mathrm{u} / \mathrm{ml})$ & ALT $(\mathrm{u} / \mathrm{ml})$ \\
\hline Diet1 (Control) & 12 & $64.00 \pm 10.27 \mathrm{~b}$ & $19.25 \pm 1.60 \mathrm{ab}$ \\
\hline Diet2 (CSM25) & 12 & $95.00 \pm 10.27 \mathrm{ab}$ & $23.00 \pm 1.60 \mathrm{a}$ \\
\hline Diet3 (CSM50) & 12 & $103.75 \pm 10.27 \mathrm{a}$ & $22.50 \pm 1.60 \mathrm{ab}$ \\
\hline Diet4 (CSM75) & 12 & $101.25 \pm 10.27 \mathrm{a}$ & $23.00 \pm 1.60 \mathrm{a}$ \\
\hline Diet5 (CSM100) & 12 & $79.50 \pm 10.27 \mathrm{ab}$ & $17.50 \pm 1.60 \mathrm{~b}$ \\
\hline
\end{tabular}

Averages followed by different letters in the same column are significantly $(\mathrm{P}<0.05)$ different. + Average of 12 fish (four fish from each aquarium). 
The estimations of serum enzyme activities of AST and ALT are taken as an indication of the amount of liver damage, as the elevated serum enzyme levels might be related to the degree of liver injury. Liver disease causes an increase in some serum enzymes by blocking their elimination into the blood (Barraza et al., 1991).

\section{Proximate analysis of whole Nile tilapia fish body.}

Chemical analysis (dry matter, protein, lipid and ash contents) at the end of a feeding trial is frequently used to determine the influence of feed on fish composition. According to Hepher (1988), endogenous factors (size, sex and stage of life cycle) and exogenous factors (diet composition, feeding frequency, temperature etc.) affect the body composition of fish. It should be noted that within exogenous factors, the composition of the feed is only the factor which could have influenced the chemical composition of fish, as other endogenous factors were maintained uniform during the study.

Results of Tables (7) showed that dry matter content ranged between 27.01 and $27.80 \%$, with insignificant differences among the different experimental groups. Compared to the control group, as the dietary CSM level increased, protein content of whole fish body significantly $(\mathrm{P}<0.05)$ decreased, while the opposite trend was observed for fat content where the increasing level of CSM in the experimental diets significantly $(\mathrm{P}<0.05)$ increased fat content of the whole fish body.

Increasing the inclusion levels of CSM in the experimental diets up to $25 \%$ had no significant effect on ash content of whole fish body, while the other replacing levels $(50,75$ or $100 \%)$ significantly $(\mathrm{P}<0.05)$ reduced ash content of the whole fish body.

In contrast to the previous results, Cheng and Hardy (2002) reported that the replacement of FM by CSM in diets of rainbow trout at levels of 5, 10, 15, or 20 $\%$ had no significant effect on moisture, fat, crude protein and ash of whole fish body.

Table 7: Least square means and standard error for the effect of replacing fish meal by cottonseed meal in Nile tilapia diets on proximate analysis of whole Nile tilapia fish body on dry matter basis.

\begin{tabular}{|l|c|c|c|c|c|}
\hline Diets & No.+ & $\begin{array}{c}\text { Dry matter } \\
\%\end{array}$ & $\begin{array}{c}\text { Crude protein } \\
\%\end{array}$ & $\begin{array}{c}\text { Crude fat } \\
\%\end{array}$ & $\begin{array}{c}\text { Ash } \\
\%\end{array}$ \\
\hline Diet1 (Control) & 24 & $27.58 \pm 0.47$ & $58.72 \pm 0.54 \mathrm{a}$ & $26.92 \pm 0.49 \mathrm{e}$ & $13.97 \pm 0.31 \mathrm{a}$ \\
\hline Diet2 (CSM25) & 24 & $27.12 \pm 0.47$ & $58.53 \pm 0.54 \mathrm{~b}$ & $27.98 \pm 0.49 \mathrm{~d}$ & $12.95 \pm 0.31 \mathrm{ab}$ \\
\hline Diet3 (CSM50) & 24 & $27.80 \pm 0.47$ & $58.33 \pm 0.54 \mathrm{~b}$ & $29 . .53 \pm 0.49 \mathrm{c}$ & $11.94 \pm 0.31 \mathrm{~b}$ \\
\hline Diet4 (CSM75) & 24 & $27.01 \pm 0.47$ & $58.46 \pm 0.54 \mathrm{~b}$ & $31.31 \pm 0.49 \mathrm{~b}$ & $10.11 \pm 0.31 \mathrm{~b}$ \\
\hline Diet5 (CSM100) & 24 & $27.37 \pm 0.47$ & $58.31 \pm 0.54 \mathrm{~b}$ & $32.88 \pm 0.49 \mathrm{a}$ & $8.14 \pm 0.31 \mathrm{c}$ \\
\hline
\end{tabular}

Averages followed by different letters in the same column are significantly $(\mathrm{P}<0.05)$ different.

+ Average of 16 fish (eight fish from each aquarium).

\section{Feed costs}

Feed cost is considered to be the highest recurrent cost in aquaculture, often ranging from 30 to $60 \%$, depending on the intensity of the operation. Any 
reduction in feed costs either through diet development, improved husbandry or other direct or indirect means is, lead to, decreases the total production investment and inereased the net return (Lovell, 1989).

Data presented in Table (8) showed that feed costs (LE / ton) decreased gradually with increasing the substitution level of FM by CSM. The decrease in feed costs was $16.08,32.17,48.25$ and $64.33 \%$ (relative to the cost of the control diet) for diets contained 25, 50, 75 and $100 \%$ CSM as replacers for FM.

Generally, results of the present experiment showed that the replacement of $25 \%$ of dietary FM by CSM (on CP basis) had no significant effect on all growth and feed utilization parameters of Nile tilapia. Also, diets contained $25 \%$ of dietary CSM as a replacer of FM had no adversed effect on hematological parameters and serum transaminases activities of Nile tilapia. Whereas, increasing the replacing level to 50,75 or $100 \%$ had almost an adversed effect on all these parameters. Moreover, results of feed costs indicated that replacing $25 \%$ of dietary FM by CSM decreased the feed costs by $16.08 \%$. Therefore, it is possible to substitutes $25 \%$ of dietary FM by CSM (on $\mathrm{CP}$ basis) in Nile tilapia diets.

Table 8: Feed costs of the experimental diets used in the experiment.

\begin{tabular}{|c|c|c|c|}
\hline Diets & Feed cost, LE / ton & Relative to control \% & Decrease in feed cost \% \\
\hline CSM0 & 3420 & 0 & 0 \\
\hline CSM25 & 2870 & 83.92 & 16.08 \\
\hline CSM50 & 2320 & 67.83 & 32.17 \\
\hline CSM75 & 1770 & 51.75 & 48.25 \\
\hline CSM100 & 1220 & 35.67 & 64.33 \\
\hline
\end{tabular}

\section{CONCLUSION}

Based on the obtained results, it is clear that the replacement of $25 \%$ of dietary FM by CSM (on CP basis) had no significant effect on all growth parameters (BW, BL, K, WG and SGR values) and feed utilization parameters (FI, FCR, and PER values) of Nile tilapia. Also, diets contained $25 \%$ dietary CSM as a replacer of FM had no adversed effect on hematological parameters (hematocrit and hemoglobin) and serum transaminases (AST and ALT) activities of Nile tilapia. Whereas, increasing the replacing level to 50,75 or $100 \%$ had almost an adversed effect on all these parameters, indicating the possibility of substituting $25 \%$ of FM by CSM in Nile tilapia diets to reduce feed cost.

\section{REFERENCES}

Alford, B. B.; Liepa, G. U. and Vanbeber, A. D. (1996). Cottonseed protein: what does the future hold? Plant Foods Human Nutrition, 49:1-11

Association of Official Analytical Chemists, AOAC (1990). Official Methods of Analysis. Washington, D. C. 
Barraza, M.I.; Coppock, C.E.; Brooks, K.N.; Wilks, D.L.; Saunders, R.G. and Latimer, Jr, G.W. (1991). Iron sulfate and feed pelleting to detoxify free gossypol in cottonseed diets for dairy cattle. J. Dairy. Sci., 74: 3457-3467.

Boyd, D. (1979). Water Quality in Warmwater Fish Ponds. Auburn University Agricultural Experiment Station, Auburn, AL.

Cheng Z.J. and Hardy, R.W. (2002). Apparent digestibility coefficients and nutritional value of cottonseed meal for rainbow trout (Oncorhynchus mykiss). Aquaculture, 212:361-372.

Dorsa, W. J.; Robinette, H. R.; Robinson, E. H. and Poe, W.E. (1982). Effects of dietary cottonseed meal and gossypol on growth of young channel catfish. Trans. Am. Fish. Soc., 111: 651- 655.

Duncan, D. B. (1955). Multiple range and multiple F-test. Biometrics, 11:1-24.

El-Saidy D. M. (1999). Evaluation of cottonseed meal as partial and complete replacement of fish meal in practical diets of Nile tilapia (Oreochromis niloticus) fingerlings. Egyptian Journal of Aquatic Biology and Fisheries, 3: 441-457.

El-Sayed, A. M. (1990). Long-term evaluation of cottonseed meal as a protein source for Nile tilapia Oreochromis niloticus (Linn.). Aquaculture, $87: 315-320$.

Garcia-Abiado, M. A.; Mbahinzireki, G.; Rinchard, J.; Lee, K. J. and Dabrowski, K. (2004). Effect of diets containing gossypol on blood parameters and spleen structure in tilapia, Oreochromis sp., reared in a recirculating system. Journal of Fish Diseases, 27: 359-368.

Hepher, B. (1988). Nutrition of pond fishes. Cambridge, Cambridge Univ. press.

Herman, R. L. (1970). Effects of gossypol on rainbow trout (Salmo gairdneri). Journal of Fish Biology, 2:293-297.

Jackson, A. J.; Capper, B. S. and Matty, A. J. (1982). Evaluation of some plant proteins in complete diets for tilapia Sarotherodon mossambicus. Aquacult., 27:97-109.

Jones, L.A. (1987). Recent advances in using cottonseed products. Proceedings of the Florida Nutrition Conference, 12-13 March 1987, Daytona Beach, FL, pp. 119-138. 
Lee, K. J.; Dabrowski, K.; Blom, J. H.; Bai, S. C. and Stromberg, P. C. (2002). A mixture of gossypol containing cottonseed meal, soybean meal and animal by-products can be used as a fish meal substitute in diets for juvenile rainbow trout (Oncorhynchus mykiss). J. Anim. Physiol. Anim. Nutr., 86: 201-213.

Lee, K. J.; Rinchard, J.; Dabrowski, K.; Babiak, I.; Ottobre, J. S. and Christensen,J. E. (2006). Long-term effects of dietary cottonseed meal on growth and reproductive performance of rainbow trout: three-year study. Animal Feed Science and Technology, 126:93-106.

Makinde, M. O. Akingbemi, B.T. and Airee, T.A. (1997). Gossypol-induced erythrocyte fragility in the rat is ameliorated by ethanol intake. South African Journal of Science, 93: 141-143.

Nilsson, L. (1992). Genetic parameters of growth and sexual maturity in Arabic Char (Salvelimus alpinus).Aquaculture, 106:9-19.

NRC (1993). National Research Council. Nutrient Requirements of Fish. National Academy Press, Washington, DC, 114 pp.

Ofojekwu, P. C. and Ejike, C. (1984). Growth response and feed utilization in the tropical cichlid,Oreachromis niloticus (Linn) fed on cottonseed-based diets. Aquacult., 42: 27-36.

Ostrowski, A.C. and Garling, D.L. (1988). Influence of anabolic hormone treatment and dietary protein ratio on condition and muscle deposition of rainbow trout. Prog. Fish Cult., 50:133-140.

Post, G. (1987). Textbook of Fish Health. T.F.H. Publications, Neptune City, NJ, USA.

Power, D.M. (1990). The physiology of growth. Trout News, 10:20-30.

Reitman, S. and Frankel, S. (1957): A colorimetric method for determination of serum glutamic oxaloacetic and glutamic pyrovic transaminases.Amer.J. Clin. Path. , 28: 56-59.

Rinchard, J.; Lee, K.J.; Czesny, S.; Ciereszko, A. and Dabrowski, K. (2003). Effect of feeding cottonseed meal containing diets to broodstock rainbow trout and their impact on the growth of their progenies. Aquacult., 227: $77-87$. 
Robinson, E.H. (1991). Improvement of cottonseed meal protein with supplemental lysine in feeds for channel catfish. J. Appl. Aquacult., 1: 1-14.

Robinson, E.H. and Daniels, W.H., (1987). Substitution of soybean meal with cottonseed meal in pond feeds for channel catfish reared at low densities. J. World Aquacult. Soc., 18: 101-106.

Robinson, E.H. and Li, M. H. (1994). Use of plant proteins in catfish feeds: replacement of soybean meal with cottonseed meal and replacement of fish meal with soybean meal and cottonseed meal. J. World Aquac. Soc., 25: 271-276.

Robinson, E.H. and Tiersch, T. R. (1995). Effects of long-term feeding of cottonseed meal on growth, testis development, and sperm motility of male channel catfish, Ictalurus punctatus broodfish. J. World Aquac. Soc., 26: 426-431.

Robinson, E. H.; Rawles, S. D.; Oldenburg, P. W. and Stickney, R. R. (1984). Effects of feeding glandless or glanded cottonseed products and gossypol to Tilapia aurea. Aquaculture, 28: 145-154.

SAS, (1996). SAS Procedure Guide "version 6.12 Ed". SAS Institute Inc., Cary, $\mathrm{NC}$, USA.

Sun, L. T.; Chen, G. R. and Chang, C. F. (1995). Acure responses of blood parameters and comatose effects in salt-acclimated tilapia exposed to low temperatures. Journal of Thermal Biology, 20: 299-306.

Wilson, R.P.; Robinson, E.H. and Poe, W.E. (1981). Apparent and true availability of amino acids from commomn feed ingredients for channel catfish. J. Nutr., 111: 923-929.

Yildirim, M.; Lim, C.; Wan, P. and Klesius, P. (2003). Growth performance and immune response of channel catfish (Ictalurus punctatus) fed diets containing graded levels of gossypol-acetic acid. Aquacult., 219: 751-768. 